\title{
Laser-Heating Characteristics of CuO-Incorporating Glasses
}

\author{
Jungki Lee, Jongwoo Kim*, and Hyungsun Kim ${ }^{\dagger}$ \\ School of Material science and Engineering, Inha University, Incheon 402-751, Korea \\ ${ }^{*}$ Current address: LG CHEM LTD, Daejeon 305-738, Korea
}

(Received January 16, 2015; Revised March 16, 2015; Accepted March 17, 2015)

\begin{abstract}
Laser sealing with glass frits appears a promising technology for sealing various electronic devices (e.g., solar cells, displays) due to its several advantages. The purpose of this study is to understand the relationship between the composition of glasses and their laser-heating conditions. To allow glass to be sealed using laser heating, $\mathrm{CuO}$ was added to two different glass systems, in different amounts. The optical absorptivity of the glass samples was related directly to their $\mathrm{CuO}$ content. The laser-heating temperature and the $\mathrm{CuO}$ content exhibited a proportional relationship. Furthermore, the heating temperature increased linearly with the laser power used. From these results, we could determine the appropriate laser-heating conditions and $\mathrm{CuO}$ content for sealing electronic devices using laser-sealing technology.
\end{abstract}

Key words : Optical absorptivity, Laser-heating, Glass, CuO, Laser sealing

\section{Introduction}

$\mathrm{G}^{\mathrm{s}}$ lass frits can be used as sealing materials for air tightening and protecting the insides of electronic devices from gases and moisture, ${ }^{1-2)}$ preventing device failure caused by water vapor. Furthermore, glass frits are chemically, thermally, and mechanically very stable. Therefore, glass frits have been studied extensively for use in sealing various electronic and electrical devices, such as plasma display panels, organic light-emitting diodes, and dye-sensitized solar cells. ${ }^{3)}$ Nevertheless, the conventional thermal sealing process causes significant damage to the rest of the device, as the temperatures involved are very high. Therefore, alternative laser-based sealing techniques, in which only the target area is heated, are being explored. ${ }^{4)}$ Laser sealing using low-glass-transition-temperature glass frits can potentially be used to form seals in electronic and electrical devices that are both durable and hermetic."

To ensure the densification of the sealing material to the proper degree without causing thermal damage during the laser-heating process, the laser-heating temperature should be controlled. Before glass can be sealed using laser heating, it is necessary to increase the optical absorptivity of the glass at the wavelength corresponding to the laser used. It is well known that the optical absorptivity of many glass systems in the visible-light spectrum increases with the addition of $d$ - and $f$-elements, such as iron, copper, chromium, and manganese. ${ }^{6-8)}$ Copper (II) oxide has been added as a constituent to various glass systems to allow them to be

${ }^{\dagger}$ Corresponding author : Hyungsun Kim

E-mail : kimhs@inha.ac.kr

Tel : +82-32-860-7545 Fax : +82-32-862-5546 heated using a laser. ${ }^{6)}$ It has been reported that the $\mathrm{Cu}^{2+}$ ions partially fill the d-orbitals and create color centers in the glass, owing to the existence of an absorption band in the visible spectrum. Energy from the irradiated laser beam is absorbed by the transition metal ions (such as those of $\mathrm{Cu}^{2+}$ through $\mathrm{d}-\mathrm{d}$ transitions) and the absorbed energy is converted into thermal energy through a non-radiative relaxation process. ${ }^{8)}$ Recently, transition-metal atom-heating processes have been studied extensively for the laserinduced treatment of glasses, including for controlling their degree of crystallization, and their morphology. ${ }^{9,10)}$

The purpose of this study was to develop glass systems that can be sealed using laser heating, by understanding the relationship between the optical absorptivity of glasses and their characteristics when heated by a laser. We investigated two different glass systems $\left(\mathrm{Bi}_{2} \mathrm{O}_{3}-\mathrm{B}_{2} \mathrm{O}_{3}-\mathrm{ZnO}\right.$ and $\left.\mathrm{SiO}_{2}-\mathrm{B}_{2} \mathrm{O}_{3}-\mathrm{Na}_{2} \mathrm{O}\right)$. Their optical absorptivity was controlled by adding $\mathrm{CuO}$ to the systems. Two different homogeneously melted $\mathrm{CuO}$-containing glass systems were produced, and the characteristics of the glasses when heated by a laser, were investigated in relation to different $\mathrm{CuO}$ content.

\section{Experimental Procedure}

\subsection{Glass fabrication}

The raw materials for the $35 \mathrm{Bi}_{2} \mathrm{O}_{3}-25 \mathrm{~B}_{2} \mathrm{O}_{3}-40 \mathrm{ZnO}$ (BBZ glass) and $66 \mathrm{SiO}_{2}-17 \mathrm{~B}_{2} \mathrm{O}_{3}-17 \mathrm{Na}_{2} \mathrm{O}$ ( $\mathrm{SBN}$ glass) mother glass systems (in mol\%) were prepared from high-purity chemical reagents $\left(\mathrm{Bi}_{2} \mathrm{O}_{3}, \mathrm{H}_{3} \mathrm{BO}_{3}, \mathrm{ZnO}, \mathrm{SiO}_{2}\right.$, and $\mathrm{Na}_{2} \mathrm{O}$; purity > 99.9\%; Sigma Aldrich, USA). CuO (> 99.9\%; Sigma Aldrich, USA) was added to the mother glasses in amounts of up to $4.4 \mathrm{~mol} \%$ to control the optical absorptivity of the 
glasses. The batches were homogeneously mixed by ball milling for $24 \mathrm{~h}$ and melted in an alumina crucible at $1100^{\circ} \mathrm{C}$ (BBZ glass) and $1300^{\circ} \mathrm{C}$ (SBN glass) for $30 \mathrm{~min}$ using an electric furnace. To form the frits, the glass melts were poured quickly on a ribbon roller and quenched. The cullets were pulverized using a planetary mono mill for $7 \mathrm{~h}$. All the prepared bulk glass samples were bubble free and were machined to have the same thickness and surface roughness.

\subsection{Characterization of glass and laser firing tem- perature}

The optical absorptivity of the glasses was measured using an ultraviolet (UV)-visible spectrometer, by making five sets of measurements for wavelengths of 340-1100 nm. The glass transition temperature $\left(\mathrm{T}_{\mathrm{g}}\right)$ was determined using a thermogravimetry-differential thermal analysis (TGDTA) system (Rigaku, Japan). The measurements were performed at a heating rate of $10^{\circ} \mathrm{C} / \mathrm{min}$, and the samples were heated to $1200^{\circ} \mathrm{C}$. The emissivity of the glasses was measured using a Fourier transform infrared spectrometry (FTIR) system (MIDAC M2410, MIDAC Corp., USA). A fiber laser (LC-aIII-Amada) with a wavelength $(\lambda)$ of 1064 $\mathrm{nm}$ was used to irradiate the surfaces of the glass samples using an objective lens (20' magnification) with increasing laser power. The laser irradiation conditions were power: $0.4-4 \mathrm{~W}$, scan rate: $50 \mathrm{~mm} / \mathrm{s}$, laser frequency: $100 \mathrm{kHz}$, laser wavelength: $1064 \mathrm{~nm}$, and spot size: $50 \mathrm{~mm}$. The temperature of the glass surface after laser heating was measured with an infrared (IR) camera (FLIR SC325, FLIR Systems Inc., UK).

\section{Results and Discussion}

The ability of a material to be heated by a laser is directly related to the optical properties of the material. The optical absorptivity of glass can be varied significantly by adding $\mathrm{CuO}$ to BBZ glass (Fig. 1(a)), and SBN glass (Fig. 1(b)). We found that the addition of $\mathrm{CuO}$ to the tested glass systems increased their absorption coefficients over the entire range of wavelengths. This phenomenon is related directly to the laser-heating characteristics of the glasses. To evaluate accurately the effect of the addition of $\mathrm{CuO}$ on the absorption coefficients of the glasses at $1064 \mathrm{~nm}$, the absorption coefficients at $1064 \mathrm{~nm}$ were measured (displayed in Fig. 2). The absorption coefficient of the BBZ-CuO glass sample increased from 2.59 to $38.68 \mathrm{~cm}^{-1}$ while that of the SBN$\mathrm{CuO}$ glass sample increased from 82.67 to $98.77 \mathrm{~cm}^{-1}$. From these results, optical absorptivity at $1064 \mathrm{~nm}$ was easily induced in the glasses by the addition of $\mathrm{CuO}$, regardless of the chemical composition of the mother glass. Furthermore, the degree of increase in the absorption coefficient at 1064 $\mathrm{nm}$ was proportional to the amount of $\mathrm{CuO}$ added.

The heating and cooling of the laser-irradiated surfaces of the glasses occurred rapidly (within $0.5 \mathrm{~s}$; see Fig. 3). This is an advantage because it prevents thermal damage to the

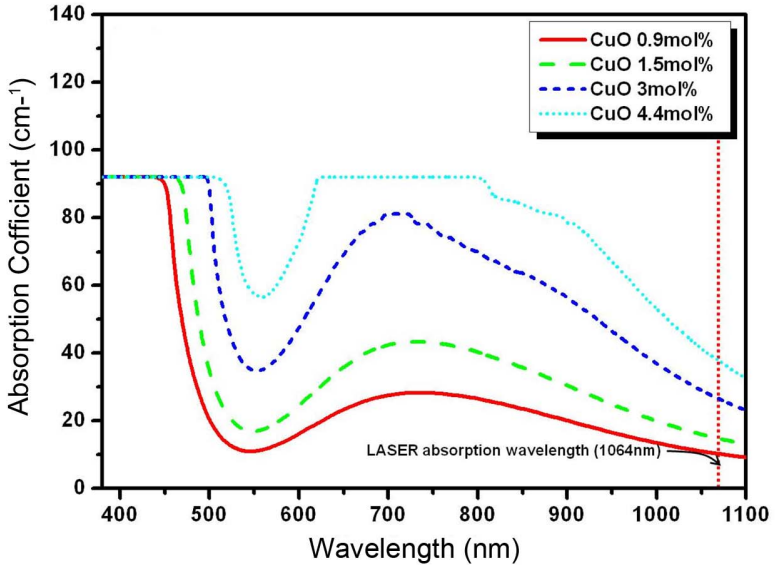

(a)

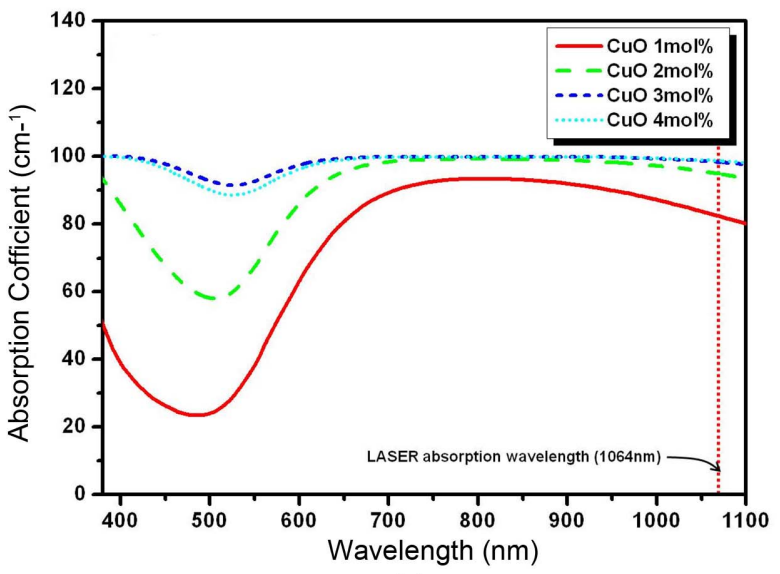

(b)

Fig. 1. Optical absorption coefficients of (a) BBZ glass and (b) SBN glass samples containing $\mathrm{CuO}$.

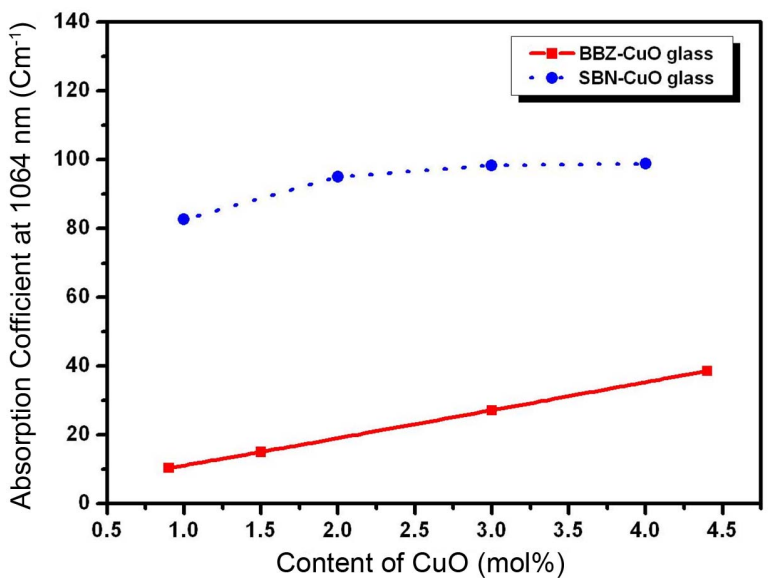

Fig. 2. Effects of $\mathrm{CuO}$ content of $\mathrm{BBZ}$ and SBN glasses on their absorption coefficients at $1064 \mathrm{~nm}$.

substrate caused by the diffusion of heat from the sealing material. The maximum laser-heating temperature was approximately $850^{\circ} \mathrm{C}$, while the minimum temperature was $130^{\circ} \mathrm{C}$. The maximum heating temperature varied with the $\mathrm{CuO}$ content, which directly affected the optical absorption 


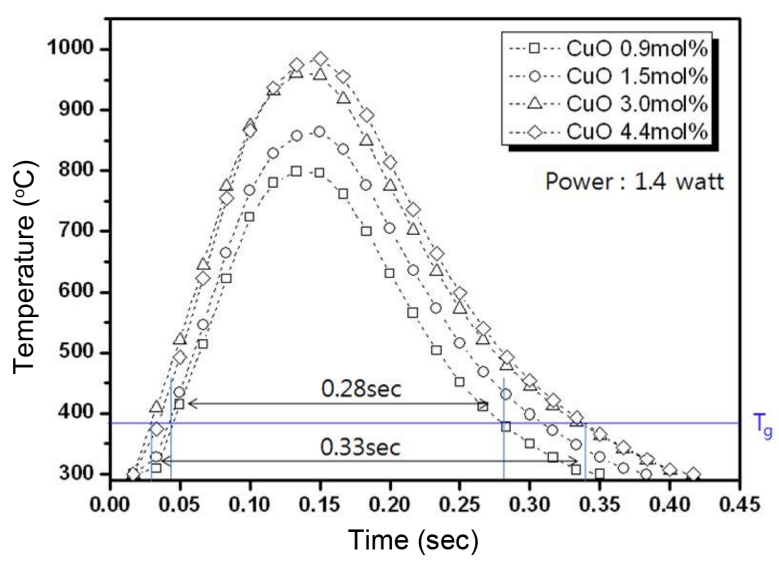

Fig. 3. Laser heating profile of BBZ-CuO glass.

coefficient at $1064 \mathrm{~nm}$.

As mentioned previously, the laser-heating temperature was proportional to the $\mathrm{CuO}$ content and the laser power used. The variations in the laser-heating temperatures of the BBZ and SBN glasses are displayed in Fig. 4. The laserheating temperature of $\mathrm{BBZ}-\mathrm{CuO}$ glass varied from $151^{\circ} \mathrm{C}$ to $850^{\circ} \mathrm{C}$ (laser power: $0.4-1.4 \mathrm{~W}$ ) while that of $\mathrm{SBN}-\mathrm{CuO}$ glass varied from $166^{\circ} \mathrm{C}$ to $1500^{\circ} \mathrm{C}$ (laser power: $0.8-5 \mathrm{~W}$ ). The increase in the absorption coefficient at $1064 \mathrm{~nm}$ with the increase in the $\mathrm{CuO}$ content may be related directly to the laser-heating temperature. The laser-heating temperatures of SBN glass samples containing 4 and $5 \mathrm{~mol} \% \mathrm{CuO}$ were similar. This was probably because the absorption coefficients of the two samples were similar.

Considering the range of glass-transition temperatures (BBZ-CuO glass: $376.1-386.8^{\circ} \mathrm{C}$; SBN-CuO glass: $601.4-$ $751.3^{\circ} \mathrm{C}$ ), the laser-firing temperatures of the two glasses were well within the range for sintering. If the temperature is too low, the heat energy available will not be enough for necking and densification to occur. On the other hand, if the temperature is too high, thermal shock can occur after laser irradiation. ${ }^{5)}$ The ability to be heated by a laser can be induced in glasses by adding $\mathrm{CuO}$ to them, while their laserheating temperature can be controlled by varying their $\mathrm{CuO}$ content, and the power of the laser used. Thus, several factors determine the laser-heating temperature, including those related to the materials and to the apparatus used. ${ }^{4-5)}$

Optical parameters such as the absorption coefficient and thermal properties are the main factors determining whether a glass can be sealed by laser irradiation, and these factors are related to the chemical composition of the glass. ${ }^{7}$ The factors depending on the apparatus used, are the type of laser used (i.e., its wavelength), as well as its power, scan rate, spot size, and irradiation time. To develop an appropriate laser-sealing technology for glass, the relationship between the laser-irradiation parameters and the laser-heating characteristics of the glass should be elucidated.

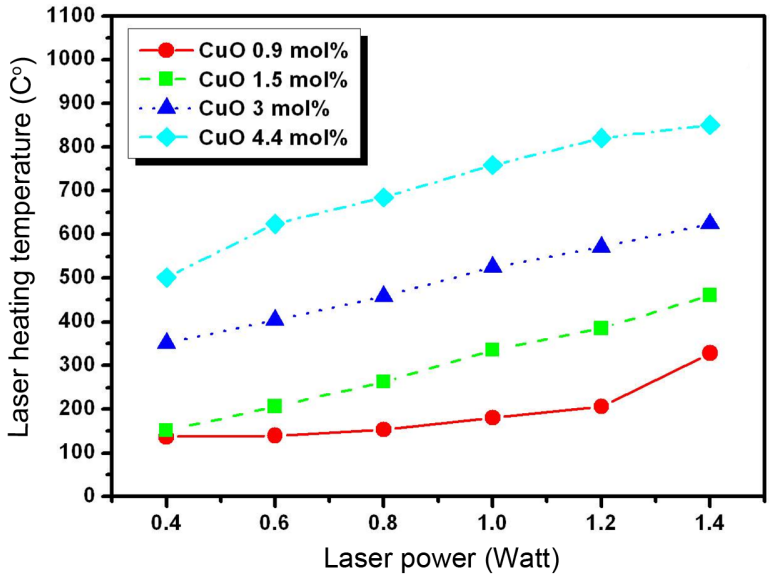

(a)

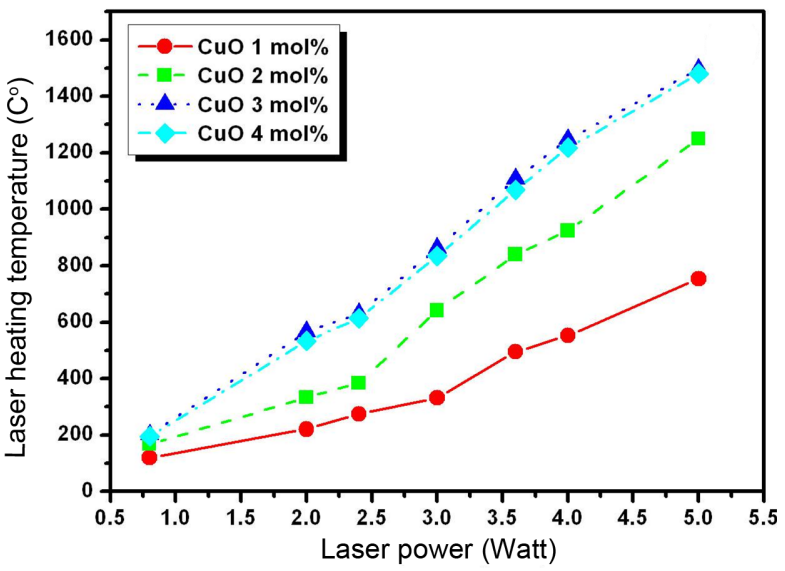

(b)

Fig. 4. Effects of $\mathrm{CuO}$ content and laser power used, on the laser-heating temperature of (a) $\mathrm{BBZ}-\mathrm{CuO}$ glass and (b) SBN glass-CuO glass.

\section{Conclusion}

The optical absorptivity values of the glasses were significantly affected by the addition of $\mathrm{CuO}$, with the absorptivity being proportional to the amount of $\mathrm{CuO}$ added. The ability to be heated by a laser could readily be induced in the glasses by adding $\mathrm{CuO}$ to them; this was regardless of the chemical compositions of the mother glass. The glasses underwent heating and cooling rapidly when irradiated with a laser. This is a major advantage from the viewpoint of preventing thermal defects in the seals formed after the heating process. The laser-heating temperatures of the glasses were related to their optical absorptivity at 1064 $\mathrm{nm}$, and to the laser power used. Considering the thermal properties of the glasses, it may be possible to deliver sufficient heat energy to them to cause sintering. However, to develop state-of-the-art laser sealing technology, the effects of various laser irradiation parameters and the inherent properties of the glass being sealed, should be studied. 


\section{Acknowledgments}

This research was supported by the Pioneer Research Center Program through the National Research Foundation of Korea, funded by the Ministry of Science, ICT \& Future Planning (Grant no. NRF-2010-0019471).

\section{REFERENCES}

1. J. Choi, D. W. Shin, and W. T. Bae, "Effect of an Additive on the Physical and Electrical Properties of the $\mathrm{B}_{2} \mathrm{O}_{3}-\mathrm{ZnO}$ $\mathrm{Bi}_{2} \mathrm{O}$ Glass System for a Sheath Heater Module(in Korean)," J. Korean Ceram. Soc., 50 [1] 57-62 (2013).

2. I. B. Lee, S. J. Hwang, and H. S. Kim, "Reaction between Oxide Sealant and Liquid Electrolyte in Dye-Sensitized Solar Cells," Sol. Energy Mater. Sol. Cells, 95 315-17 (2011).

3. R. Sastrawan, J. Beier, U. Belledin, S. Hemming, A. Hinsch, R. Kern, C. Vetter, F. M. Petrat, A. Prodi-Schwab, P. Lechner, and W. Hoffmann, "New Interdigital Design for Large Area Dye Solar Modules Using a Lead-free Glass Frit Sealing," Prog. Photovolt: Res. Appl., 14 697-709 (2006).

4. F. Börner, W. Lippmann, A. Hurtado, and B. Schön, "Glasses for Laser Joining of Zirconia Ceramics," J. Eur.
Ceram. Soc., 34 765-72 (2014).

5. R. Cruz, J. A. C. Ranita, J. Maçaira, F. Ribeiro, A. M. B. Silva, J. M. Oliveira, M. H. F. V. Fernandes, H. A. Ribeiro, J. G. Mendes, and A. Mendes, "Glass-Glass Laser-Assisted Glass Frit Bonding," IEEE Trans. Comp. Packag. Technol., 2 [12] 1949-56 (2012).

6. K. Koshiba, T. Honma, Y. Benino, and T. Komatsu, "Patterning and Morphology of Nonlinear Optical $\mathrm{Gd}_{\mathrm{x}} \mathrm{Bi}_{1-\mathrm{x}} \mathrm{BO}_{3}$ Crystals in CuO-doped Glass by YAG Laser Irradiation," Appl. Phys. A, 89 981-86 (2007).

7. B. S. Bae and M. C. Weinberg, "Optical Absorption of Copper Phosphate Glasses in the Visible Spectrum," J. NonCrys. Solids, 168 223-31 (1994).

8. T. Honma, P. T. Nguyen, and T. Komatsu, "Crystal Growth Behavior in CuO-doped Lithium Disilicate Glasses by Continuous-wave Fiber Laser Irradiation," J. Ceram. Soc. Jpn., 116 [12] 1314-18 (2008).

9. A. Streltsov, J. Dickinson, R. Grzybowski, D. Harvey, S. Logunov, A. Ozturk, J. Surtherland, and M. Potuzak, "Laser Texturing of Doped Borosilicate Glasses," Proc. SPIE, 7584 75840S-1-12 (2010).

10. H. Sugita, T, Honma, Y. Benino, and T. Komatsu, "Formation of $\mathrm{LiNbO}_{3}$ Crystals at the Surface of $\mathrm{TeO}_{2}$-based Glass by YAG Laser-induced Crystallization," Solid State Commun., 143 280-84 (2007). 